\title{
Transcranial Sonography and Cerebral Circulatory Arrest in Adults: A Comprehensive Review
}

\author{
Juan Antonio Llompart-Pou, ${ }^{1}$ Josep Maria Abadal, ${ }^{1}$ Albrecht Güenther, ${ }^{2}$ Luis Rayo, ${ }^{1}$ \\ Juan Pedro Martín-del Rincón, ${ }^{1}$ Javier Homar, ${ }^{1}$ and Jon Pérez-Bárcena ${ }^{1}$ \\ ${ }^{1}$ Servei de Medicina Intensiva, Hospital Universitari Son Espases, Carretera Valldemossa 79, 07010 Palma, Spain \\ ${ }^{2}$ Hans Berger Clinic for Neurology, University Hospital Jena, 07743 Jena, Germany \\ Correspondence should be addressed to Juan Antonio Llompart-Pou; juanantonio.llompart@ssib.es
}

Received 16 August 2012; Accepted 9 September 2012

Academic Editors: N. Gibney and J. F. Stover

Copyright (C) 2013 Juan Antonio Llompart-Pou et al. This is an open access article distributed under the Creative Commons Attribution License, which permits unrestricted use, distribution, and reproduction in any medium, provided the original work is properly cited.

\begin{abstract}
The diagnosis of brain death remains a clinical challenge for intensive care unit physicians. Worldwide regulations in its diagnosis may differ, and the need of ancillary tests after a clinical examination is not uniform. Transcranial sonography is a noninvasive, bedside, and widely available technique that can be used in the diagnosis of the cerebral circulatory arrest that preceeds brain death. In this paper we review the general concepts, the technical requisites, the patterns of Doppler signal confirming cerebral circulatory arrest, the vessels to insonate, and the options in cases with poor acoustic window. Future research perspectives in the field of transcranial sonography are discussed as well.
\end{abstract}

\section{Introduction}

The diagnosis of clinical death in many critically ill patients has evolved from a cardiopulmonary event to the development of brain death, which is characterized by the irreversible loss of brain function $[1,2]$. Involved pathophysiology in the development of brain death varies depending on the predominant location of the brain injury. This location can be divided into primarily supratentorial or infratentorial damage or global damage (secondary brain injury) [3]. Increased intracranial pressure (ICP) and a loss in cerebral autoregulation due to various mechanisms may gradually affect cerebral blood flow and lead to cerebral circulatory arrest (CCA) [3].

The diagnosis of brain death remains a clinical diagnosis and it can be usually declared when brainstem reflexes, motor responses, and respiratory drive are absent in patients with massive brain injuries $[1,2]$. Clinical tests must be performed following strict criteria and prerequisites. Under some circumstances, it is for necessary, the realization of ancillary tests to confirm the diagnosis $[1-3]$.

\subsection{Prerequisites [1-3]}

(i) Clarification of the etiology of coma, mainly by means of cranial computed tomography or magnetic resonance imaging in accordance to medical history review.

(ii) Exclude potential causes of loss of brain stem function. For example, acute arterial hypotension, hypothermia, which may mimic complete and irreversible brain injury and therefore the body temperature should be above $32^{\circ} \mathrm{C}$ or $90^{\circ} \mathrm{F}$, drug intoxication and acute and severe metabolic causes of coma (glucose, electrolytes, acid-base, or endocrine disturbances) have to be ruled out.

1.2. Clinical Diagnosis of Brain Death. Includes the following [1-3].

(i) Coma nonreactive to painful or verbal stimuli.

(ii) Absence of brain stem reflexes. 
(iii) Abolished response to atropine [4]. This test is required by Spanish law [4], but it is not required in many countries [2], that is, USA. This exploration evaluates the caudal medullary function. An abolished response consists of the inability to increase cardiac rate by $10 \%$ after administering $0.04 \mathrm{mg} / \mathrm{kg}$ of atropine.

(iv) Abolished response to the apnea test [3].

1.3. Ancillary Tests. The confirmation of irreversibility varies depending on the national guidelines [2]. In most cases, an extended observation period is enough to confirm the diagnosis [2]. In Spain, the observation period for patients with structural brain damage is of 6 hours and 24 hours in cases with global ischemic damage [4]. Although confirmatory tests also result in a shortening of the period necessary to diagnose a brain death status, providing organ harvesting in improved conditions, they are not free of controversy [5] and are mandatory in only $40 \%$ of the countries [2].

In Spain, the confirmatory tests can be divided into the following [4].

(i) Those evaluating neuronal function:
(a) electroencephalography,
(b) evoked potentials.

(ii) Those evaluating cerebral blood flow:
(a) cerebral angiography,
(b) digital substraction angiography,
(c) cerebral scintigraphy,
(d) transcranial sonography.

Other complementary techniques that have been recently shown to have promising results in the diagnosis of CCA [3], such as cranial computed angiography [6], magnetic resonance imaging and magnetic resonance angiography [7], bispectral index monitoring [8], and ultrasound perfusion imaging [9], warrant additional studies and cannot be routinely recommended [10].

In our environment, the most commonly used ancillary test is the electroencephalography. However, it cannot be used in patients who have received long-term sedatives, which is common in the ICU environment. In such cases, the most widely 24-hours/7-days available technique is transcranial sonography, which is usually performed by trained intensivists or neurologists.

The aim of this paper was to evaluate the application of transcranial sonography in the diagnosis of CCA. This includes the general concepts, the technical requisites, the patterns of Doppler signal confirming CCA, the vessels to insonate, and the options in cases with poor acoustic window.

\section{Transcranial Sonography}

2.1. General Remarks. Transcranial sonography is a noninvasive, safe, and bedside technique used to evaluate the circulation of the basal arteries in neurocritically ill patients [11] and especially in the diagnosis of the CCA that preceeds brain death [12]. It has to be underlined that these are not identical conditions. Between the development of CCA and total loss of brain function there may be a lag not exceeding 24 hours [12]. Transcranial sonography has been used in the diagnosis of CCA from 1987 [13, 14].

To perform a transcranial sonography as a confirmatory test after a clinical diagnosis of brain death, some prerequisites are mandatory to avoid false results $[3,15,16]$.

(i) Evidence of brain injury.

(ii) The exploration has to be performed by trained physicians with experience in the technique and familiar with the pathophysiology of brain death.

(iii) The patient must be hemodynamically stable (systolic arterial pressure higher than $90-100 \mathrm{mmHg}$ ), avoiding hypothermia less than $32^{\circ} \mathrm{C}$, must be normocapnic (pCO2 35-45 mmHg), and, in the absence of marked metabolic derangements, conditions that are per se necessary to evaluate brain death.

2.2. Technical Requisites. The system must be equipped with a $2 \mathrm{MHz}$ pulsed-wave Doppler probe, using a sample volume lower than $10 \mathrm{~mm}[1,16,17]$. Both transcranial Doppler (TCD) [13-15] and transcranial color coded sonography (TCCS) have been used as a confirmatory test in the study of the CCA which preceeds brain death $[17,18]$. Using TCCD, the operator can correct angle of insonation to follow. This angle of insonation must be kept within 0-60 degrees.

2.3. Patterns of Doppler Signal Confirming Cerebral Circulatory Arrest. The increase of ICP and subsequent decrease in CPP occurring in devastating brain injuries results in progressive changes in the Doppler spectra waveform [15, 16]. When ICP equals diastolic blood pressure, the brain is only perfused in systole. In this stage, the end-diastolic velocity in the Doppler spectra is zero. When ICP equals mean arterial pressure, brain perfusion ceases. In this stage, the Doppler spectra typically show an oscillating flow. When ICP reaches the systolic blood pressure, sharp systolic spikes are present in the transcranial sonography examination. With time, the acoustic signal disappears.

In summary, the following Doppler sonographic patterns can be found:

(i) Increasing pulsatility of the Doppler waveform: it represents the increase in ICP. The existence of any anterograde diastolic flow does not correspond to a CCA pattern (Figure 1).

The pulsatility index (PI) is a common measure for describing the shape of signal waveforms. High PI is usually correlated with high intracranial pressure. It is calculated by the following formula:

$\mathrm{PI}=($ peak systolic velocity - end diastolic velocity $) /$ mean velocity (reference values in healthy subjects $0.86 \pm 0.15$ in MCA) [19]. 


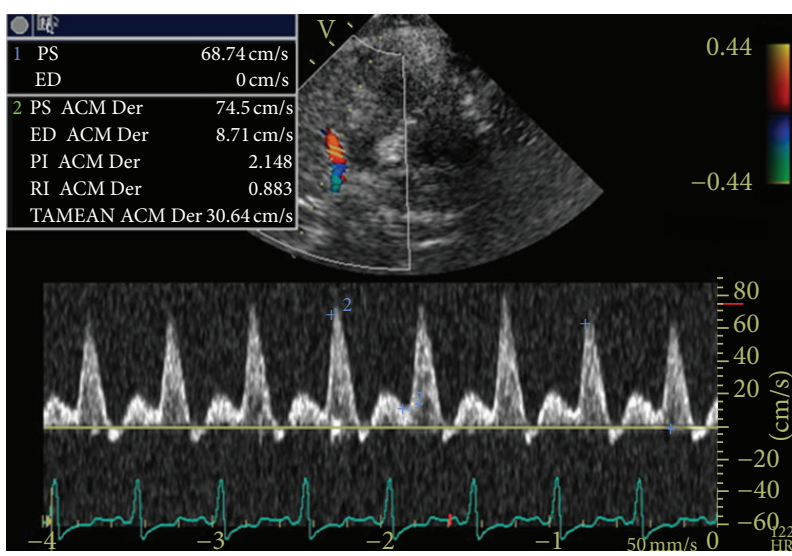

FIGURE 1: Middle cerebral artery (M1) shows a minimal retrograde diastolic flow but the rest of the cycle shows a persistent diastolic flow that is not compatible with cerebral circulatory arrest. This was a 23-year-old male who suffered a traumatic brain injury developing refractory intracranial pressure that was treated with high-dose barbiturates. This pattern reflected high intracranial pressure (ICP $43 \mathrm{mmHg}$ at the time of examination) with a pulsatility index of 2.14 .

The resistance index (RI) described by Pourcelot is a measure of peripheral flow resistance and is calculated by the following formula:

$\mathrm{RI}=$ (peak systolic velocity - end diastolic velocity)/peak velocity (reference values in healthy subjects $0.56 \pm 0.06$ in MCA) [19].

(ii) Oscillating Flow: in this pattern, anterograde systolic flow is associated with a retrograde diastolic flow representing the reverberating movement of the blood in the cerebral vessels. When the anterograde and retrograde flow are nearly equal (the area under the envelope of the positive and negative deflection is nearly the same), the cerebral perfusion has ceased. This pattern corresponds to the angiographic appearance of CCA (Figure 2) [20].

(iii) Systolic Spikes: when ICP equals systolic blood pressure, an early systolic spike pattern is usually observed in the Doppler spectra. These sharp systolic spikes must present a systolic peak less than $50 \mathrm{~cm} / \mathrm{sec}$ and a duration less than $200 \mathrm{msec}$. Filters should be set at the lowest levels to avoid misinterpretations. This pattern corresponds to the diagnosis of CCA (Figure 3).

If the systolic spikes does not fill the above-mentioned criteria, CCA cannot be diagnosed (Figure 4).

(iv) Lack of Signal: the use of this pattern in the diagnosis of CCA is controversial, since the lack of acoustic signal can be secondary to ultrasonic transmission problems. To consider this pattern as a CCA one, an exploration showing flow in the vessels to insonate in the same conditions and by the same (experienced)

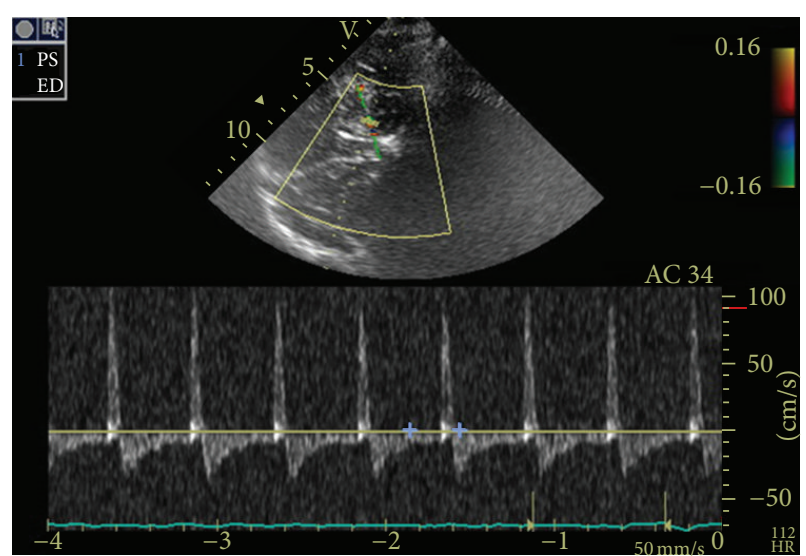

FIgURE 2: Middle cerebral artery (M1) shows a typical pattern of oscillating flow. This was a 30-year-old female admitted due to severe meningitis with refractory intracranial pressure. This pattern was compatible with cerebral circulatory arrest.

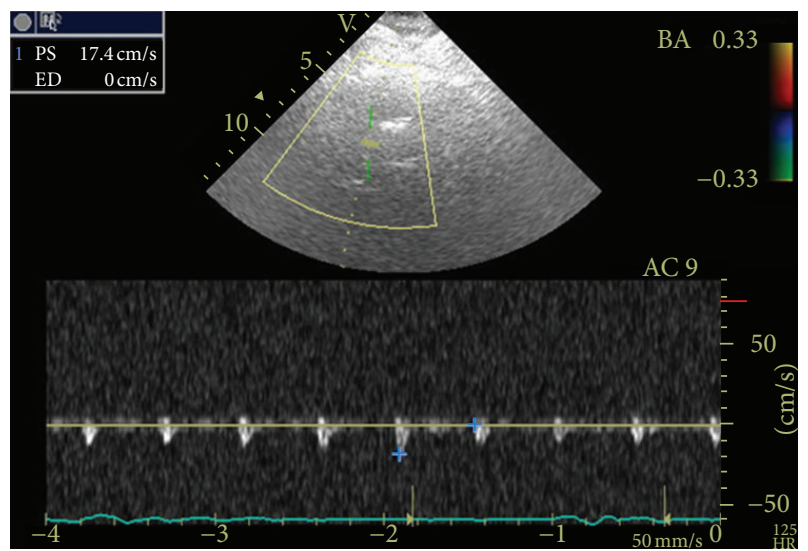

FIgURE 3: Basilar artery shows a systolic spikes pattern. Note that peak intensity is lower than $50 \mathrm{~cm} / \mathrm{sec}$ and peak width lower than $200 \mathrm{msec}$. This pattern was obtained by insonation through the foramen magnum at a depth of $82 \mathrm{~mm}$ in a 65 -year-old female who presented a severe hemorrhagic stroke.

operator has to be previously performed. This is a major limitation of transcranial sonography in the diagnosis of CCA, accounting for $10 \%$ of the cases.

2.4. Vessels to Insonate. Which vessels best correspond to the CCA has been a matter of debate. Both the extracranial and intracranial arteries have been studied. We recommend to insonate both middle cerebral arteries (MCAs) and the basilar artery (BA) [4].

Studies have evaluated internal carotid, middle cerebral, anterior cerebral, vertebral arteries, and basilar artery [21-24] with different results. The evaluation of the internal carotid artery may not appropriately reflect the progression of the CCA, since $20 \%$ of the patients could present anterograde 


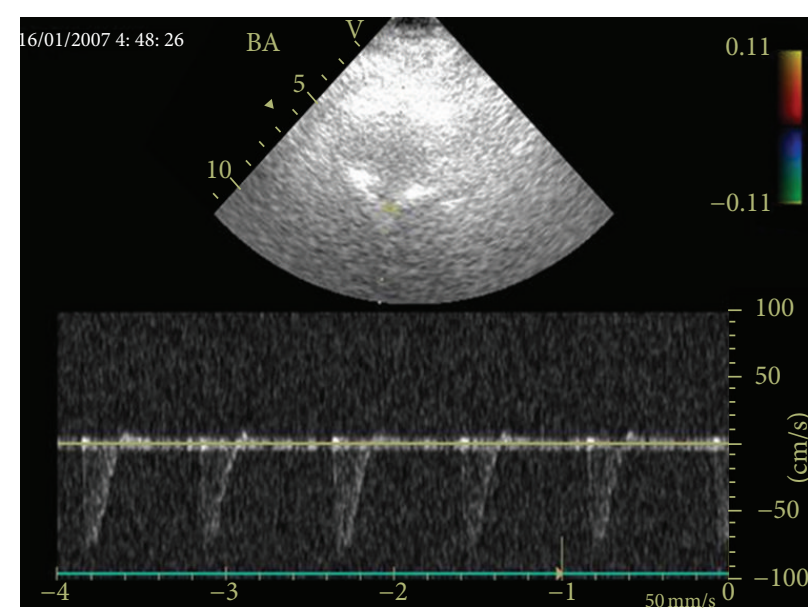

FIGURE 4: Although diastolic flow is absent, basilar artery shows anterograde systolic spikes with peak intensity higher than $50 \mathrm{~cm} /$ sec and a wide peak width in a 54-year-old male with severe brain injury. The clinical examination showed a preserved response to the apnea test. Therefore, this pattern was not compatible with cerebral circulatory arrest.

diastolic flow in spite of presenting CCA [25]. One mechanism for persistence of flow in the ICA with clear evidence of intracranial circulatory arrest involves direct shunting of blood from the ICA into the external carotid system without perfusion of the brain [25]. Another potential hypothesis is that, in some patients, arrest of blood flow may occur at a higher level than the carotid bifurcation [25]. On the other hand, different studies have shown that the study of the BA is of paramount importance to avoid false positive results $[24,26]$, since it is well known that the BA supplies the brainstem and in the diagnosis of brain death we actually evaluate the brain stem function [24].

It is recommended to insonate both MCA and BA showing a CCA pattern (oscillating flow or systolic spikes) in two different explorations separated by 30 minutes. The rationale behind this recommendation relies on the assumption that transitory patterns compatible with CCA have been described in patients with rebleeding after subarachnoid hemorrhage, and after cardiac arrest, and, in the fact that, 30 minutes is sufficient to confirm the irreversibility of a CCA pattern $[15,16]$.

2.5. Special Circumstances. The above-mentioned criteria are applicable in the presence of an intact skull $[15,16]$. The presence of ventricular drains, large craniectomies, or skull fractures can affect the Doppler spectra sonogram and show persistent diastolic flow in cases with demonstrated brain death, similarly to what occurs in children less than 1-yearold in whom fontanelles are still open [27]. In most cases, it is attributable to the loss of skull hermetism [27]. Another potential cause relies in the dissociation between the carotid and the vertebrobasilar circulation as a consequence of a primary injury to the brain stem [28]. Improved results in terms of sensitivity and specificity can be achieved with the addition of the cervical extracranial internal carotid artery insonation in sequential examinations [28].

2.6. What to Do in Cases with Poor Acoustic Window? In cases of difficult acoustic window, some authors have successfully used an ophthalmic approach to increase the number of conclusive studies. The transorbital imaging of the carotid siphon reflects the sonographic pattern of the anterior circulation [29, 30]. Lampl et al. [29] improved their positive findings using this approach from $79 \%$ to $88 \%$ of the cases. Dominguez-Roldan et al. [30] successfully used this approach in 10 patients with impossibility to obtain a sonographic pattern by the temporal approach.

In our experience, the use of ultrasound contrast agents (UCAs) to maximize the acoustic signal results in an increase of the number of conclusive studies. Since patients in whom we evaluate the existence of CCA have devastating injuries and low acoustic signal, the use of UCAs can be a relevant tool. With TCCS technology, we evaluated the benefit of using UCAs in 50 patients with CCA. A conclusive pattern of CCA was obtained in $90 \%$ of the patients in the TCCS exploration, which improved to $98 \%$ after using UCAs. This fact minimizes the need of a previous study in cases with poor acoustic window [18], which, as previously stated, constitutes the major limitation with this technique.

\section{Conclusions}

Transcranial sonography is a noninvasive, bedside, and widely available technique that can be used in the diagnosis of the CCA that preceeds brain death. A meta-analysis published in 2006 including the ten most relevant articles to date in a large population of 684 patients stated that its sensitivity was $89 \%$ and specificity $99 \%$ [31]. The report of the American academy of neurology stated that sensitivity ranges from $91 \%$ to $100 \%$ and specificity from $97 \%$ to $100 \%$ when performed after a clinical examination of brain death [32]. Whether specificity achieves $100 \%$ or not is a relevant issue. Repeated examinations may increase specificity. Regarding sensitivity, it is very unlikely that $100 \%$ can be reached since $10 \%$ of the patient lack of acoustic window [31]. However, it has to be noted that all complementary techniques present limitations when used as a confirmatory tool of brain death [5].

In addition, one must keep in mind that in cases with isolated brain stem damage with subsequent clinical brain death, the transcranial sonography examination can show maintained flow. The effect of severe hyperventilation can also result in modifications of the sonographic pattern due to cerebral vasoconstriction. These facts highlight the need of a rigorous protocol to rule out potential confounders.

In these authors' opinion, transcranial sonography is a valid technique in the diagnosis of CCA when used by experienced operators. In addition, it is noninvasive, nonexpensive, and can be performed bedside. The potential usefulness and the limitations of this technique have been 
discussed. Such limitations should be taken into account by physicians who perform and interpret the results.

In our opinion, different points remain to be elucidated in future research. Some of them are listed below.

(i) Can we use both TCD and TCCS ultrasound devices?

(ii) If accepted that both MCAs and BA represent the mandatory vessels to insonate in patients with CCA, should we accept any alternative if those vessels cannot be obtained?

(iii) In the systolic spikes pattern, a maximum systolic peak $50 \mathrm{~cm} / \mathrm{sec}$ and duration of $200 \mathrm{msec}$ is accepted. These recommendations are based on early studies $[13,14]$. Should we refute or confirm them?

(iv) Should we reject the lack of signal pattern with the increasing use of recently developed UCAs?

In summary, transcranial sonography constitutes a useful tool in the diagnosis of the cerebral circulatory arrest that preceeds brain death when physicians are familiar with strict diagnostic criteria and know the underlying pathophysiology. However, some points remain to be elucidated and, in these authors' opinion, an update of the criteria stated by the consensus conference [15] regarding the above-mentioned points is required.

\section{References}

[1] E. F. M. Wijdicks, "The diagnosis of brain death," The New England Journal of Medicine, vol. 344, no. 16, pp. 1215-1221, 2001.

[2] E. F. M. Wijdicks, "Brain death worldwide: accepted fact but no global consensus in diagnostic criteria," Neurology, vol. 58, no. 1, pp. 20-25, 2002.

[3] A. Günther, H. Axer, J. A. Llompart Pou, O. W. Witte, and C. Terborg, "Determination of brain death: an overview with a special emphasis on new ultrasound techniques for confirmatory testing," Open Critical Care Medicine Journal, vol. 4, pp. 35-43, 2011.

[4] Real Decreto, 2070/1999, de 30 de diciembre, por el que se regulan las actividades de obtención y utilización clínica de órganos humanos y la coordinación territorial en material de donación y trasplante de órganos y tejidos.

[5] E. F. M. Wijdicks, "The case against confirmatory tests for determining brain death in adults," Neurology, vol. 75, no. 1, pp. 77-83, 2010.

[6] D. Escudero, J. Otero, L. Marqués et al., "Diagnosing brain death by CT perfusion and multislice CT angiography," Neurocritical Care, vol. 11, no. 2, pp. 261-271, 2009.

[7] A. H. Karantanas, G. M. Hadjigeorgiou, K. Paterakis, D. Sfiras, and A. Komnos, "Contribution of MRI and MR angiography in early diagnosis of brain death," European Radiology, vol. 12, no. 11, pp. 2710-2716, 2002.

[8] B. Vivien, X. Paqueron, P. Le Cosquer, O. Langeron, P. Coriat, and B. Riou, "Detection of brain death onset using the bispectral index in severely comatose patients," Intensive Care Medicine, vol. 28, no. 4, pp. 419-425, 2002.

[9] J. M. Abadal, J. A. Llompart-Pou, J. Homar, J. Velasco, J. Ibáñaz, and J. Pérez-Bárcena, "Ultrasonographic cerebral perfusion in assessment of brain death: a preliminary study," Journal of Ultrasound in Medicine, vol. 27, no. 5, pp. 791-794, 2008.
[10] E. F. M. Wijdicks, P. N. Varelas, G. S. Gronseth, and D. M. Greer, "Evidence-based guideline update: determining brain death in adults: report of the quality standards subcommittee of the American Academy of Neurology," Neurology, vol. 74, no. 23, pp. 1911-1918, 2010.

[11] J. M. Abadal, J. A. Llompart-Pou, J. Homar, J. Pérez-Bárcena, and J. Ibáñez, "Applications of transcranial color-coded duplex sonography in monitoring neurocritical patients," Medicina Intensiva, vol. 31, no. 9, pp. 510-517, 2007.

[12] L. Dosemeci, B. Dora, M. Yilmaz, M. Cengiz, S. Balkan, and A. Ramazanoglu, "Utility of transcranial Doppler ultrasonography for confirmatory diagnosis of brain death: two sides of the coin," Transplantation, vol. 77, no. 1, pp. 71-75, 2004.

[13] F. J. Kirkham, S. D. Levin, T. S. Padayachee, M. C. Kyme, B. G. R. Neville, and R. G. Gosling, "Transcranial pulsed Doppler ultrasound findings in brain stem death," Journal of Neurology Neurosurgery and Psychiatry, vol. 50, no. 11, pp. 1504-1513, 1987.

[14] A. H. Ropper, S. M. Kehne, and L. Wechsler, "Transcranial Doppler in brain death," Neurology, vol. 37, no. 11, pp. 1733-1735, 1987.

[15] X. Ducrocq, W. Hassler, K. Moritake et al., "Consensus opinion on diagnosis of cerebral circulatory arrest using Dopplersonography: task Force Group on cerebral death of the Neurosonology Research Group of the World Federation of Neurology," Journal of the Neurological Sciences, vol. 159, no. 2, pp. 145-150, 1998.

[16] T. Segura, S. Calleja, P. Irimia, and J. I. Tembl, "Recommendations for the use of transcranial Doppler ultrasonography to determine the existence of cerebral circulatory arrest as diagnostic support for brain death," Reviews in the Neurosciences, vol. 20, no. 3-4, pp. 251-259, 2009.

[17] J. Poularas, D. Karakitsos, G. Kouraklis et al., "Comparison between transcranial color doppler ultrasonography and angiography in the confirmation of brain death," Transplantation Proceedings, vol. 38, no. 5, pp. 1213-1217, 2006.

[18] J. A. Llompart-Pou, J. M. Abadal, J. Velasco et al., "Contrastenhanced transcranial color sonography in the diagnosis of cerebral circulatory arrest," Transplantation Proceedings, vol. 41, no. 5, pp. 1466-1468, 2009.

[19] J. Krejza, Z. Mariak, J. Walecki, P. Szydlik, J. Lewko, and A. Ustymowicz, “Transcranial color Doppler sonography of basal cerebral arteries in 182 healthy subjects: age and sex variability and normal reference values for blood flow parameters," American Journal of Roentgenology, vol. 172, no. 1, pp. 213-218, 1999.

[20] W. Hassler, H. Steinmetz, and J. Pirschel, "Transcranial Doppler study of intracranial circulatory arrest," Journal of Neurosurgery, vol. 71, no. 2, pp. 195-201, 1989.

[21] G. R. De Freitas and C. André, "Sensitivity of transcranial Doppler for confirming brain death: a prospective study of 270 cases," Acta Neurologica Scandinavica, vol. 113, no. 6, pp. 426-432, 2006.

[22] E. Fages, J. I. Tembl, G. Fortea et al., "Clinical usefulness of transcranial Doppler in diagnosis of brain death," Medicina Clinica, vol. 122, no. 11, pp. 407-412, 2004.

[23] A. C. Nebra, B. Virgós, S. Santos et al., "Clinical diagnostic of brain death and transcranial Doppler, looking for middle cerebral arteries and intra cranial vertebral arteries. Agreement with scintigraphic techniques," Revista de Neurologia, vol. 33, no. 10, pp. 916-920, 2001.

[24] Y. Zurynski, N. Dorsch, I. Pearson, and R. Choong, “Transcranial Doppler ultrasound in brain death: experience in 140 
patients," Neurological Research, vol. 13, no. 4, pp. 248-252, 1991.

[25] G. R. De Freitas, C. André, M. Bezerra, R. G. Nunes, and M. Vincent, "Persistence of isolated flow in the internal carotid artery in brain death," Journal of the Neurological Sciences, vol. 210, no. 1-2, pp. 31-34, 2003.

[26] M. Hadani, B. Bruk, Z. Ram, N. Knoller, R. Spiegelmann, and E. Segal, "Application of transcranial Doppler ultrasonography for the diagnosis of brain death," Intensive Care Medicine, vol. 25, no. 8, pp. 822-828, 1999.

[27] C. Cabrer, J. M. Domínguez-Roldan, M. Manyalich et al., "Persistence of intracranial diastolic flow in transcranial Doppler sonography exploration of patients in brain death," Transplantation Proceedings, vol. 35, no. 5, pp. 1642-1643, 2003.

[28] A. Conti, D. G. Iacopino, A. Spada et al., "Transcranial doppler ultrasonography in the assessment of cerebral circulation arrest: improving sensitivity by trancervical and transorbital carotid insonation and serial examinations," Neurocritical Care, vol. 10, no. 3, pp. 326-335, 2009.

[29] Y. Lampl, R. Gilad, Y. Eschel, M. Boaz, A. Rapoport, and M. Sadeh, "Diagnosing brain death using the transcranial Doppler with a transorbital approach," Archives of Neurology, vol. 59, no. 1, pp. 58-60, 2002.

[30] J. M. Dominguez-Roldan, P. I. Jimenez-Gonzalez, C. GarciaAlfaro, V. Rivera-Fernandez, and F. Hernandez-Hazañas, "Diagnosis of brain death by transcranial Doppler sonography: solutions for cases of difficult sonic windows," Transplantation Proceedings, vol. 36, no. 10, pp. 2896-2897, 2004.

[31] L. M. Monteiro, C. W. Bollen, A. C. Van Huffelen, R. G. A. Ackerstaff, N. J. G. Jansen, and A. J. Van Vught, "Transcranial Doppler ultrasonography to confirm brain death: a meta-analysis," Intensive Care Medicine, vol. 32, no. 12, pp. 1937-1944, 2006.

[32] M. A. Sloan, A. V. Alexandrov, C. H. Tegeler et al., "Assessment: transcranial Doppler ultrasonography. Report of the Therapeutics and Technology Assessment Subcommittee of the American Academy of Neurology," Neurology, vol. 62, no. 9, pp. 1468-1481, 2004. 


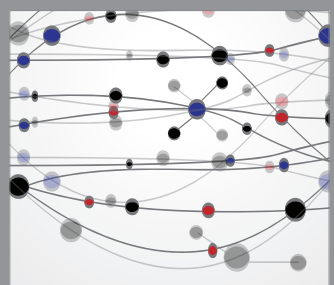

The Scientific World Journal
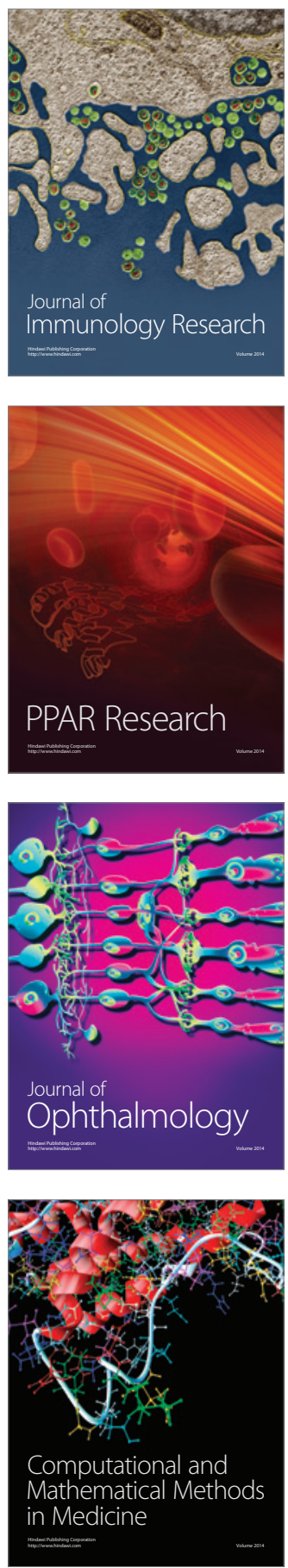

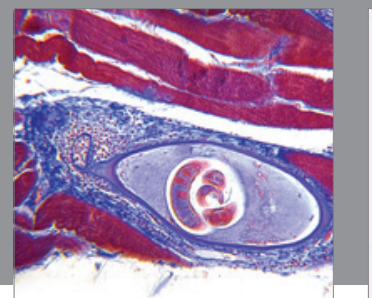

Gastroenterology

Research and Practice
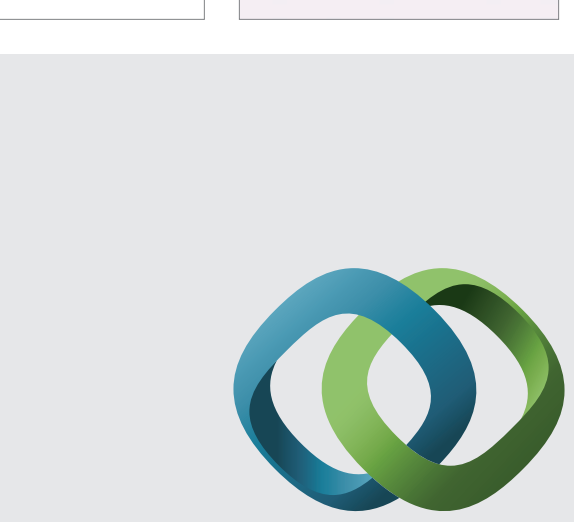

\section{Hindawi}

Submit your manuscripts at

http://www.hindawi.com
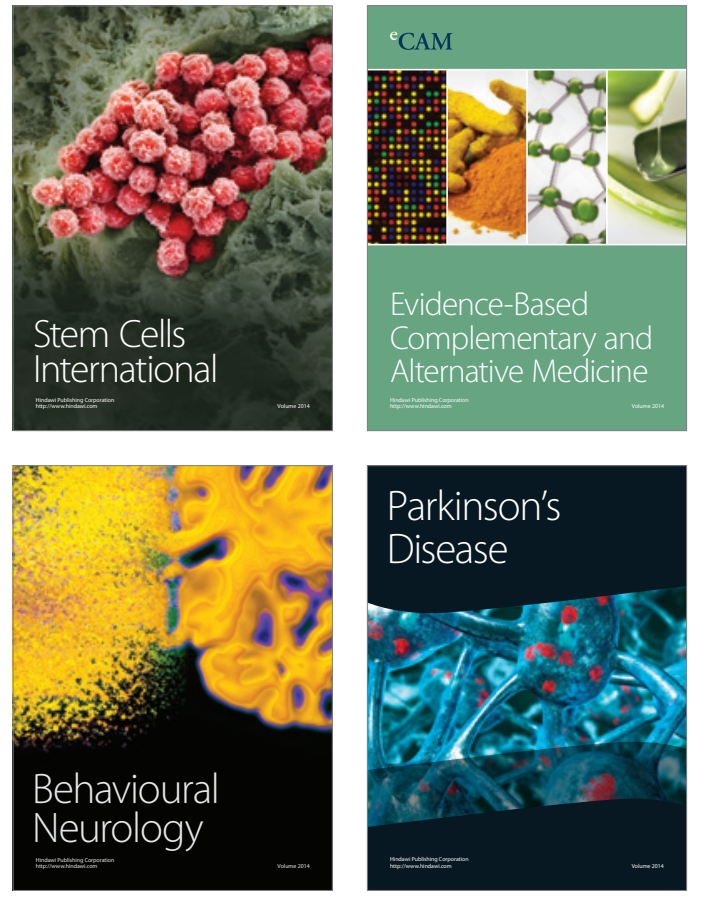
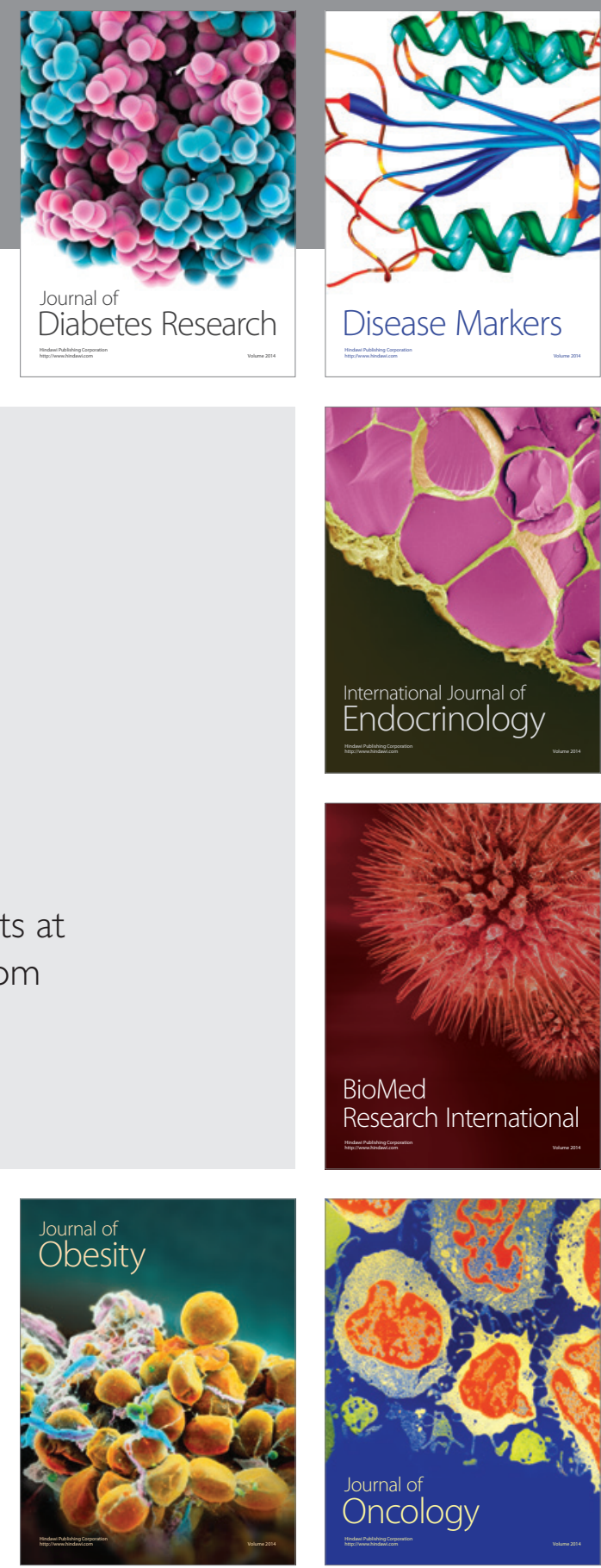

Disease Markers
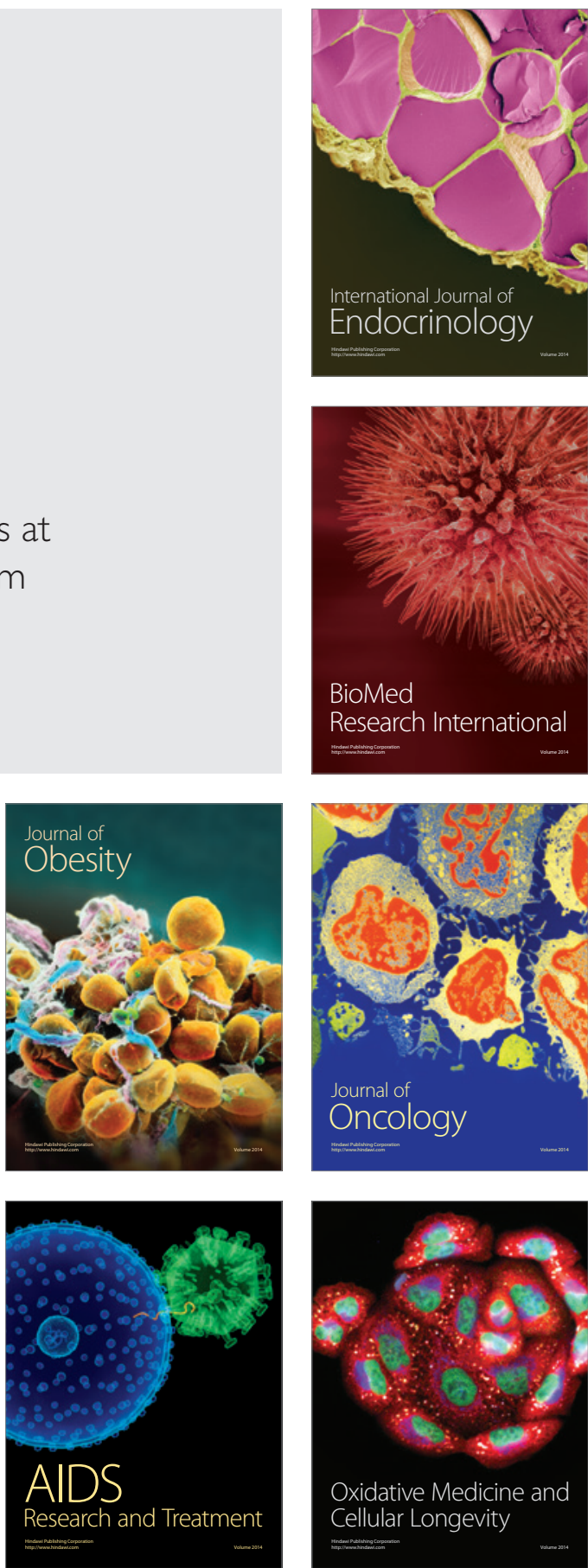